\title{
Liebe Leserin und lieber Leser!
}

Sie halten das e \& i-Sonderheft anlässlich der Emeritierung von Herrn O. Univ.-Prof. Dipl.-Ing. Dr. techn. Richard Eier in Hãnden. Für alle, die Herm Eier persönlich kennen gelemt haben, wohl eine Überraschung: Wer denkt schon, wenn die Rede auf Herm Prof. Eier kommt, an einen Emeritus!

Das vorliegende Heft soll die mannigfaltigen Leistungen von Herm Prof. Eier würdigen und muss sich somit in mehrfacher Hinsicht auf eine Zeitreise begeben. Sind es die aktuellen Forschungsthemen auf der einen Seite, so sind es die Bahn brechenden Entwicklungen des vergangenen Jahitunderts auf der anderen Seite, die in diesem Heft von kompetenten Autoren beschrieben werden. Dabei tritt eine Vielfalt an Sichtweisen hervor, welche die vielfältigen Interessen Richard Eiers widerspiegeln. Dementsprechend vielfältig und umfangreich ist dieses Sonderheft auch geworden.

Als Leittiguren, die das Lebenswerk von Richard Eier geprägt haben, erkennt man nur unschwer den leider schon verstorbenen Universitätsprofessor Dr. Gūnther Kraus und den noch immer hoch aktiven Universitảtsprofessor Dr. Heinz Zemanek. Es ist Prof. Zemanek vorbehalten, seinen Schüler Richard Eier im ersten Beitrag aus seiner Sicht vorzustellen. Dabei wird auch gleich der Nährooden für Prof. Eiers Arbeiten, bestehend aus Fernmeldetechnik, Nachrichtentechnik, Datenverarbeitung und Computertechnik bis hin zur Informationstheorie, als ein gewaltiges Gebäude treffend charakterisiert.

Dass Herr Prof. Eier schon immer weit vorausschauend war, zeigt die Geschichte seines Instituts. Von 1973 an, als das Institut für Datenverarbeitung gegründet worden ist, bis zum heutigen Tag hat die Innovationskraft von Prof. Eier zu zahlreichen Kontakten mit der Industrie und zu vielen erfolgreichen Spin-offs von Institutsmitgliedern geführt.

Die folgenden Aufsätze geben Ausblicke auf technische Entwicklungen durch unterschiedliche Fenster. Die Maus im Labyrinth, die Diplomarbeit des Jubilars, wird in den Kontext der fünfzigjährigen Geschichte der Kybernetik in Ǒsterreich gesetzt. Sie dokumentiert die Vorliebe Prof. Eiers für analytisches Denken und zugleich die Liebe zu innovativem, feinmechanischem Detail. Der Pioniergeist Osterreichischer Forscher wird durch eine Beschreibung der frühen Arbeiten von Robert v. Lieben heraufbeschworen. Die Arbeiten von Robert v. Lieben wurden von Universitătsprofessor Pichler neu zusammengetragen und gewürdigt. Ósterreichischer Pioniergeist spiegelt sich auch in den folgenden Beitrāgen wider. Technisch-wissenschaftlichen Spitzenleistungen, erfolgreichem Unternehmertum und visionären Grenzbetrachtungen sind die weiteren Beitrăge dieses Sonderheftes gewidmet.

Hohes wissenschaftliches Niveau, verbunden mit dem Nachweis praktischer Relevanz der erzielten Ergebnisse kennzeichnet die beiden nachfolgenden Artikel zur Sicherheit in verteilten Systemen mit skalierbarer Fehlertoleranz einerseits und

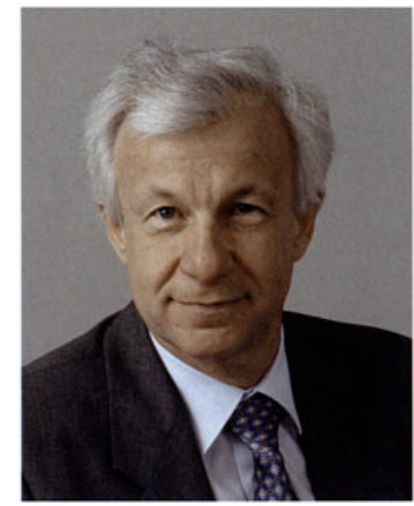

Dr. Helmut Maileck OVE

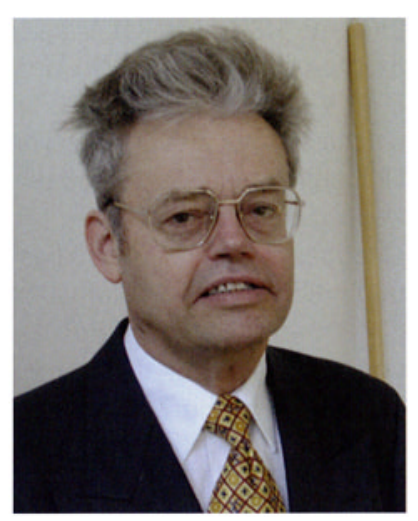

Univ.-Prof. Dr. Hans Weinrichter OVE zur Herabsetzung der Bitfehlerwahrscheinlichkeit in Funksystemen mit Mehr-Antennen-Elementen andererseits.

Als Schüler von Prof. Eier ist zu vorderst der Unternehmer Dipl.-Ing. Hannes Bardach mit seinem weltweit erfolgreich agierenden Unternehmen Frequentis zu nennen. In seinem Beitrag beschreibt er die praktische Umsetzung einer erfolgreichen Kunden-/Herstellerbeziehung im Rahmen eines strukturierten Soltware-Entwicklungsprozesses. Im Ziviltechniker Hon.-Prof. Dr. Kurt Judman ist die Kombination von Untemehmer und Ingenieur in idealer Weise manifestiert. Er beleuchtet in seinem Beitrag die frühzeitige Einbindung von Fachleuten bei Projektplanung und Projektvergabe. In seiner Arbeit mit dem Titel Computerarchitektur versus Vergaberecht wird dieses Anliegen sehr eindrucksvoll und nachvollziehbar dargestellt. Der weit gespannte Themenbogen dieses Heftes schließt mit einer Zukunftsvision für Sprachkommunikation und Internet unter der Annahme, dass in Zukunft Bandbreite, Prozessorieistung, Speicherkapazităt und Frequenz im Überfluss vorhanden sein werden.

Bei großen Entwicklungen ist oft der Weg das Ziel. Herr Prof. Eier hat seinen Weg ein großes Stück sehr erfolgreich zurückgelegt. Er kann zufrieden auf das von ihm Geschaffene zurückblicken. Wir alle, seine Wegbegleiter und der OVE, wünschen inm für seinen weiteren Lebensweg das Allerbeste, viel Glūck, Gesundheit und ungebrochene Lebensfreude!

Herzlichst

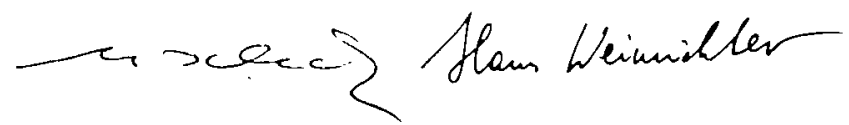

Helmut Malleck 